\title{
Retention Forces of Implant-Supported Single Crowns and Fixed Dental Prostheses after Cementation: An In-Vitro Study
}

\author{
Shaza Bishti *(D), Jousef Siouri, Stefan Wolfart (D) and Taskin Tuna \\ Department of Prosthodontics and Biomaterials, Medical Faculty, RWTH Aachen, University Aachen, \\ 52074 Aachen, Germany; jousef.siouri@googlemail.com (J.S.); swolfart@ukaachen.de (S.W.); \\ ttuna@ukaachen.de (T.T.) \\ * Correspondence: sbishti@ukaachen.de; Tel.: +49-(0)-241-80-80897
}

check for updates

Citation: Bishti, S.; Siouri, J.; Wolfart, S.; Tuna, T. Retention Forces of Implant-Supported Single Crowns and Fixed Dental Prostheses after Cementation: An In-Vitro Study. Oral 2022, 2, 29-40. https://doi.org/ $10.3390 /$ oral2010005

Academic Editor: Michele Cassetta

Received: 30 November 2021

Accepted: 7 February 2022

Published: 11 February 2022

Publisher's Note: MDPI stays neutral with regard to jurisdictional claims in published maps and institutional affiliations.

Copyright: (C) 2022 by the authors. Licensee MDPI, Basel, Switzerland. This article is an open access article distributed under the terms and conditions of the Creative Commons Attribution (CC BY) license (https:// creativecommons.org/licenses/by/ $4.0 /)$.

\begin{abstract}
The aim of this in vitro study was to investigate three different cements for their suitability to provide semi-permanent cementation, and to compare the retention forces of implant-supported single crowns (SC) and three-unit fixed dental prostheses (FDP) luted with these cements. Twenty-four methacrylate models were supplied with three implants/abutments each to simulate the condition of SCs/FDPs. Cobalt-chromium frameworks were fabricated, sandblasted $\left(\mathrm{Al}_{2} \mathrm{O}_{3} / 50 \mu \mathrm{m} / 0.2 \mathrm{MPa}\right)$ then cemented with glass-ionomer (KTC), polycarboxylate (DUR) or self-adhesive resin cement (RXU). Specimens were stored in a saline-solution $\left(\mathrm{NaCl} / 37^{\circ} \mathrm{C} / 24 \mathrm{~h}\right)$ or subjected to thermocycling. A universal testing machine and a pull-off device were used to remove the copings. The multi-factor ANOVA showed that the retention force differed significantly among all cements for the SCs after $\mathrm{NaCl}$ storage $(p<0.05)$. Mean retention forces (in Newtons) after $\mathrm{NaCl}$ storage were (SCs/FDPs): KTC 170/352, DUR 409/406, RXU 265/426, and after thermocycling (SCs/FDPs): KTC 156/262, DUR 306/380, RXU 494/508. FDPs showed higher retention values in comparison to SCs. For SCs, artificial aging with thermocycling resulted in a significant retention increase for RXU, whereas the retention of KTC and DUR was decreased. Glass ionomer can be used as a semi-permanent cement for both SCs and FDPs. Polycarboxylate cement is considered semi-permanent after one year of aging.
\end{abstract}

Keywords: implant-supported restoration; cement; retention; fixed dental prosthesis; retrievability

\section{Introduction}

The use of dental implants has enriched the treatment options in prosthetic dentistry and is highly beneficial for the improvement of quality of life especially for edentulous [1], as well as for partially edentulous patients [2]. High survival rates have been reported for implant-supported restorations (97.2\% after 5 years and 95.2\% after 10 years); however, the prevalence of peri-implantitis 2 years after placement was 34\% (patient level) and 21\% (implant level) based on recent studies $[3,4]$. These rates represent therefore a major dental health burden. For this reason, ease of retrievability of prosthetic restorations is necessary, which is of course given in removable restorations, but difficult to some extent in fixed dental restorations. Implant-supported fixed prosthetic restorations can be either cemented or screw-retained and according to recently published systematic reviews, there seems to be no significant difference between both, in terms of implant and restoration survival [5-8]. The choice of fixation method seems to be rather based on the clinician's preference [5,9]. The main reasons for using screw-retained implant restorations are controllable retrievability $[10,11]$ and superb marginal integrity [12]. However, this type of restoration requires optimal implant positioning for ideal placement of screw access holes, which otherwise might promote complications associated with esthetic, occlusion, and ceramic strength issues [13]. In comparison to screw-retention, cement-retained implant restorations are reported to offer advantages, such as a better esthetic appearance and veneering stability due to the elimination of the screw access holes $[14,15]$. Furthermore, there are noticeable 
lower costs because of less laboratory work, fees, and fewer components [13]. Moreover, the risk of loosening the restoration retaining screws is reduced. In addition, the cement layer can compensate minor discrepancies that may occur between the crown and abutment (passive fit) [16,17]. For clinicians, the usage of cement-retained implants reduces chair-side time, simplifies treatment planning and clinical procedures, as the techniques are similar to those used for conventional restorations [18].

However, the most disadvantageous aspects of cemented restorations are the higher inflammation potential of the peri-implant tissue especially for constructions with deep subgingival margins $[19,20]$, as well as the difficult and non-predictable retrievability of the superstructure in case of complications.

Since the likelihood of technical or biological complications of a restoration or an implant over time is known, a definitive cementation would, in fact, contradict the wish of retrievability $[13,21]$.

To counteract difficulties in retrievability of cemented restorations, designs for customized abutments and superstructures were introduced [10]. Further methods for retrieving a cemented superstructure were suggested, such as cutting a horizontal groove on the oral side of the restoration, to ease restoration loosening using tools with high impact pulse (e.g., Coronaflex, Kavo Dental GmbH, Warthausen, Germany). Some authors tested the usage of petroleum jelly with polyurethane resin to reduce the retention forces of the cement [22]. Others recommended the use of provisional luting agents to facilitate retrievability. However, disadvantages of these agents are low tensile strength and high solubility, promoting the washing out of the luting agents leading to marginal leaking. This, in turn, can favor the accumulation of plaque and subsequently cause an inflammation of the peri-implant tissue $[23,24]$.

Several studies have previously reported the possibility of semipermanent fixation of implant restorations $[25,26]$. This method uses cements, that allow easy retrievability of the restorations whenever required. However, these studies evaluated the retrievability of single implant restorations. To our knowledge, there is a lack of studies investigating the retrievability of other types of cemented restorations such as multi-unit fixed dental prostheses (FDPs).

Therefore, the aim of this in vitro study was to investigate and compare the retention forces of implant-retained single crowns (SCs) and three-unit fixed dental prostheses (FDPs) cemented with three different types of commercially available cements.

The null hypotheses to be tested were as follows:

- There is no difference regarding the retention and removal attempts of SCs and FDPs.

- Thermocycling does not influence the retention of the cements.

\section{Materials and Methods}

\subsection{Preparation of Implant Models}

Twenty-four implant models were produced out of methacrylate for the simulation of single crowns (SCs) or fixed dental prostheses (FDPs) conditions. Therefore, each model was supplied with three parallel-placed implants (Figure 1). All models were numbered in order to avoid mismatch.

First, the length of 72 abutments with a diameter of $4.3 \mathrm{~mm}$ and cone angles of $5^{\circ}$ (CAMLOG Biotechnologies AG, Switzerland) was reduced from $11 \mathrm{~mm}$ to $6 \mathrm{~mm}$ (Figure 1a). A vertical rotation lock with a length of $5 \mathrm{~mm}$ and a depth of $0.5 \mathrm{~mm}$ was milled into the abutment using a hard alloy bur (Figure $1 \mathrm{~b}$ ). Thereafter, a vacuum-formed template was produced on a Kavo study model (Kavo, Biberach, Germany) to transmit the position of the teeth 12,14, 16 into the methacrylate blocks $(2 \times 4 \times 1 \mathrm{~cm})$ (Figure 1c), and implants were inserted accordingly (Figure 1d). A precision milling unit (D-F 44, Harnisch + Rieth, Winterbach, Germany) was used to mill the rotation lock within the abutments and to prepare the boreholes for the implants to assure parallelism within the methacrylate blocks. 

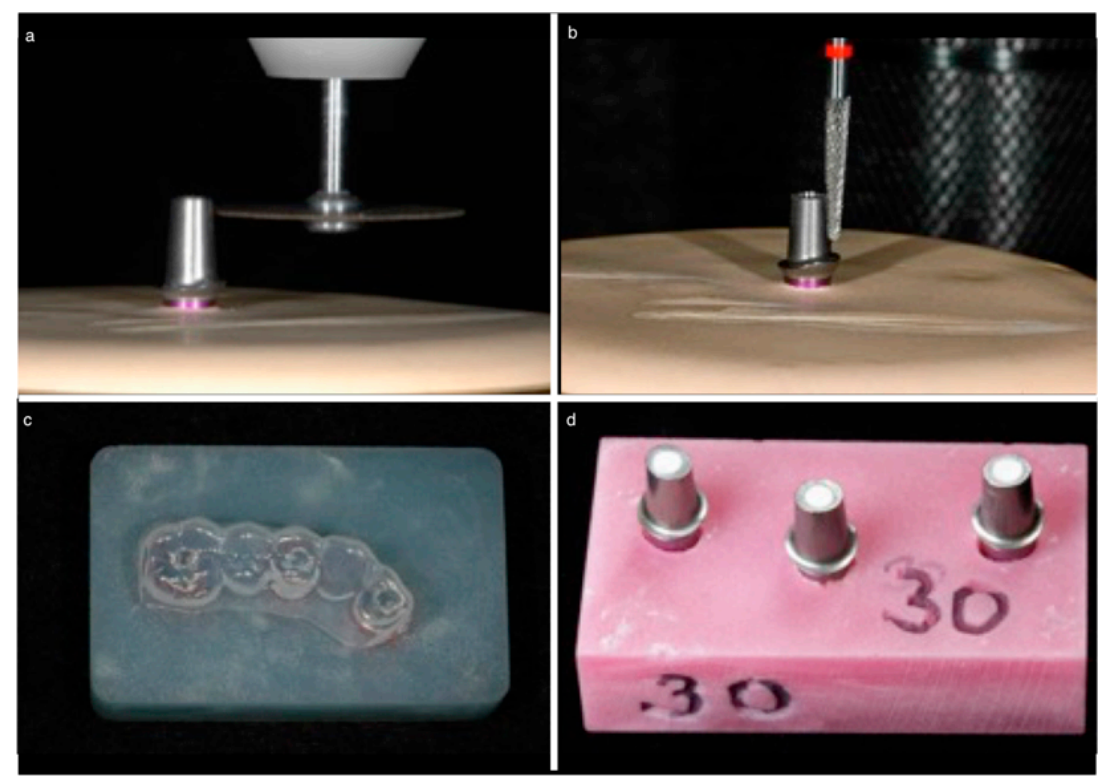

Figure 1. Production of implant models. (a) Use of a cutting disk adjusted to shorten the abutment to a length of $6 \mathrm{~mm}$; (b) use of a bur adjusted to mill a tapered groove at length of $5 \mathrm{~mm}$ and depth of $0.5 \mathrm{~mm}$ for anti-rotation lock (c) Placement of the deep-drawn film (teeth 12,14,16) for optimal positioning of the implants in the methacrylate block, (d) parallel-placed lab analogs with mounted abutments in one of the 24 models $(2 \times 4 \times 1 \mathrm{~cm})$.

\subsection{Preparation of Frameworks}

Next, the frameworks were fabricated on three adjacent abutments, in order to simulate the FDP condition. For the pull-off tests of SCs, the frameworks were cemented only on the middle abutment.

The abutments were first coated with wax caps, and connected together with wax strands. A set of anchorage loops were added to the occlusal surface to allow tensile testing with the Universal Testing Machine (UTM) (Zwick Z030, Ulm, Germany) and to facilitate the dynamic loading procedures (Figure 2a). The base of the framework was designed for the application of the CORONAflex pull-off device (Kavo, Biberach, Germany). Finally, the frameworks were cast from a cobalt-chromium alloy (Girobond NB, ArmannGirrbach, Pforzheim, Germany) and polished for final use (Figure $2 b, c)$.
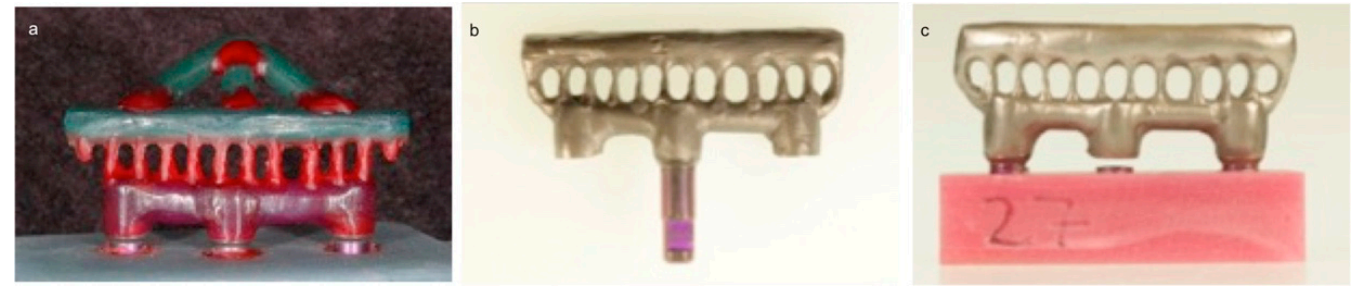

Figure 2. Fabrication of metal frameworks. (a) Wax modelling of a framework; (b) simulation of single crowns (SCs) by placing the framework on only one implant analog; (c) simulation of fixed dental prostheses (FDPs) by placing the framework on the lateral implant analogs of one implant model.

All abutments were screwed to the implants with a torque wrench (CAMLOG Biotechnologies AG, Basel, Switzerland) at a torque of $20 \mathrm{Ncm}$. To compensate for the setting effect, all screws were tightened again after $10 \mathrm{~min}$ [27]. Then, the screw-access openings of the abutments were filled with white gutta-percha (Gutta-percha in sticks, Dentsply DeTrey, Konstanz, Germany). While the first and third coping of the framework were used for the FDPs, the coping in the middle of the framework was used for the SCs (Figure 2). 


\subsection{Gap Measurement between Copings and Abutments}

Before beginning retrievability tests, the discrepancy between the abutments and superstructure was measured according to Brawek et al. 2013 [28]. These measurements were carried out to check and ensure similar circumstances between the manufactured frameworks and to ensure simulation of the in vivo condition [29].

For the examination of the margin and the mid-axial discrepancy, three implant models (i.e., nine implants) were chosen representatively. The copings of the frameworks were filled up with light green body silicone (President Light Body Green, Colténe, Konstanz, Germany) and placed on the abutments. After setting, the frameworks were removed from the implant models and filled with heavy orange body silicone (President Heavy Body Orange, Colténe, Konstanz, Germany) to remove the layer of the light green silicone out of the crown. Afterwards, the layers were cut into four slices in the mesio-distal and bucco-oral direction. The thickness of the light green silicone, which represented the gap between the abutment and the crown, was measured using a light microscope with a corresponding digital camera and software (Axio Image M2m, AxioCam MRC, AxioVision 4.8, Zeiss, Oberkochen, Germany).

\subsection{Cementation Procedure}

All FDPs were cemented with a cement band of $3 \mathrm{~mm}$ at the margin of the copings. The SCs were divided into two groups: one group was cemented with a $3 \mathrm{~mm}$ cement band, whereas the other group was cemented with a $6 \mathrm{~mm}$ band.

For the cementation, the inner surface of the crowns was manually cleaned and airabraded with $50 \mu \mathrm{m} \mathrm{Al}_{2} \mathrm{O}_{3}$ at a pressure of $0.2 \mathrm{MPa}$. The abutments were steam-cleaned, and cement residues were removed with a plastic curette (universal implant deplaquer; KerrHawe, Bioggio, Switzerland). All specimens were wiped with a cotton gauze drenched in $96 \%$ alcohol, air-dried, then visually inspected.

Three different types of dental cements were used: glass-ionomer cement (KTC) $\left(\operatorname{Ketac}^{\mathrm{TM}} \mathrm{Cem}, 3 \mathrm{M}\right.$ Espe, St. Paul, MN, USA), polycarboxylate cement (DUR) (Durelon ${ }^{\mathrm{TM}}$, $3 \mathrm{M}$ Espe, St. Paul, MN, USA), and self-adhesive resin cement (RXU) (RelyX ${ }^{\mathrm{TM}}$ Unicem, 3M Espe, St. Paul, MN, USA). The cementation was carried out according to manufacturers' instructions. After cementation, the castings were manually pressed together for $10 \mathrm{~s}$ then loaded with a molding press for $10 \mathrm{~min}$. The molding press had a compressive force of $50 \mathrm{~N}$ at the elected height of the castings (Figure 3).

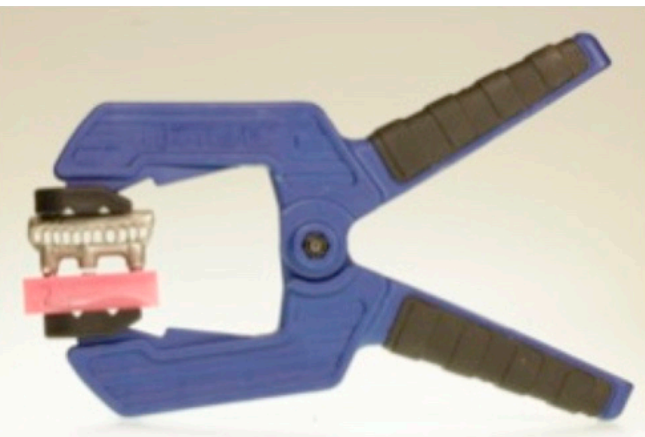

(a)

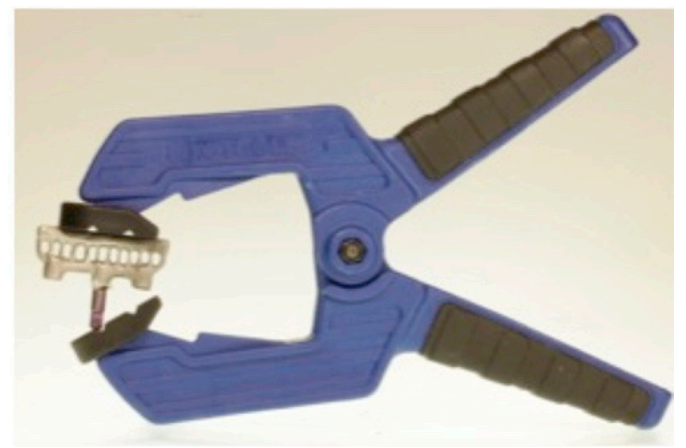

(b)

Figure 3. Fixed castings with the molding press with a force of 50 N. (a) FDP; (b) SC.

After setting, cement residues were removed with a plastic curette. Half of the specimens were stored in isotonic saline solution (Isotonic Saline Solution 0.9\%, Braun, Melsungen, Germany) for $24 \mathrm{~h}$ at a temperature of $37^{\circ} \mathrm{C}(\mathrm{NaCl}$ group), whereas the other half (Thermo group) was exposed to thermocycling with 10,000 cycles at $+5^{\circ}$ and $+55^{\circ} \mathrm{C}$ ("hard thermocycling") with a dwell time of $30 \mathrm{~s}$ [30]. The 10,000 thermocycles correlate with the aging of the cement for one year in a patients' mouth and represent mechanical 
stresses and fluid flows [31,32]. The complete workflow of all groups is shown in detail in Figure 4.

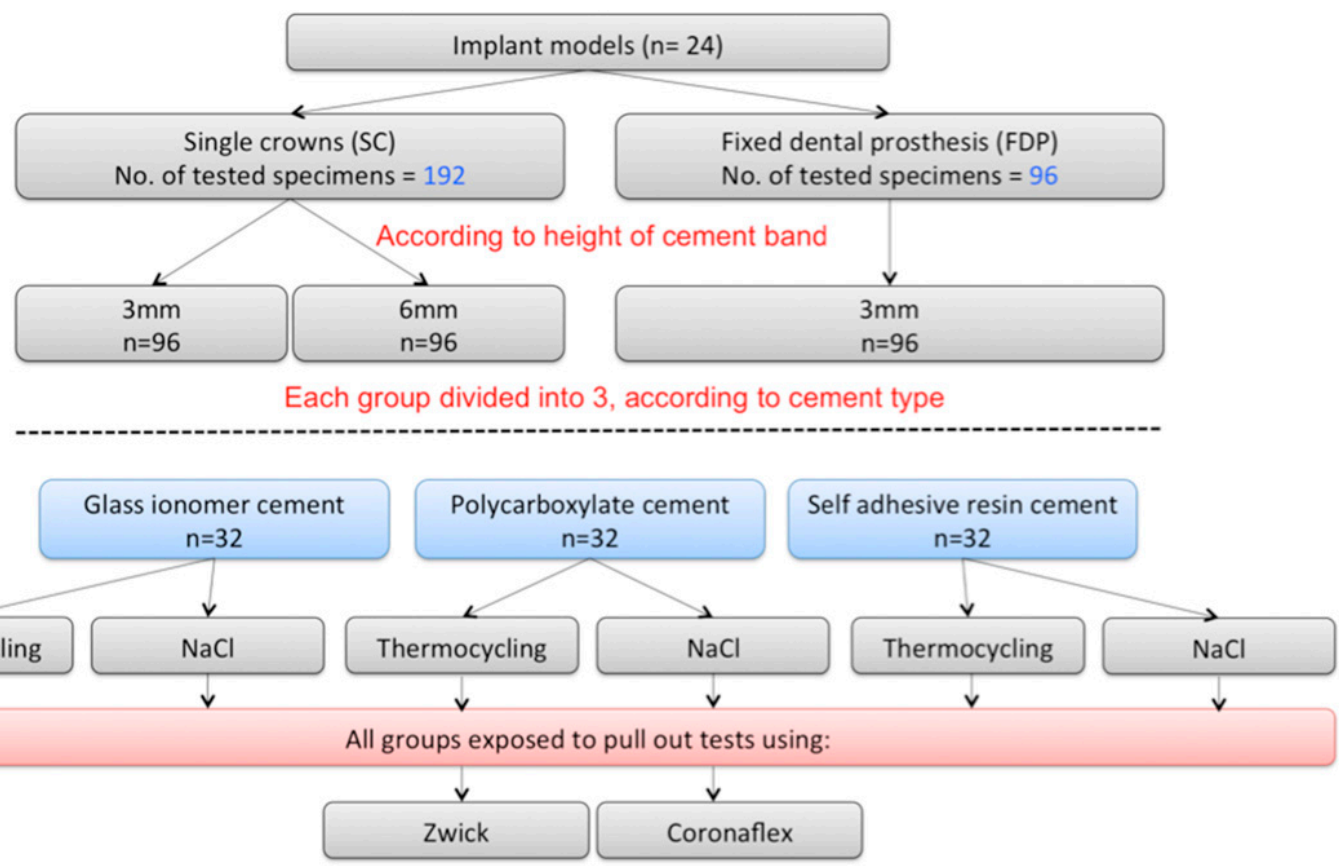

Figure 4. Workflow of the tests.

To remove the copings, the CORONAflex (Cflex)(Kavo, Biberach, Germany) was used on half of the models and the Universal Testing Machine (UTM) (Zwick Z030, Ulm, Germany) on the other half. To remove the restorations with the UTM, the tensile load was applied using a $10 \mathrm{kN}$ load cell and a constant crosshead speed of $1 \mathrm{~mm} / \mathrm{min}$. For testing the SCs, the attachment point for the pull-off was the occlusal loop above the middle coping. For the FDPs, the midpoint of the framework was used as a fixation point for the pull-off device.

The Coronaflex (drive pressure: 2.5-3.5 MPa, impact force $4000 \mathrm{~N}$ ) was used at 3 adjustable levels (lowest, middle, highest). Firstly, the lowest adjustable level was used and after 10 attempts, of which 5 were mesial and 5 distal, the level was increased.

Every test cycle included two modes of storage, each cement type and both pull-out tests (Figure 5). Four test cycles were completed to achieve a total number of 8 specimens per subgroup.

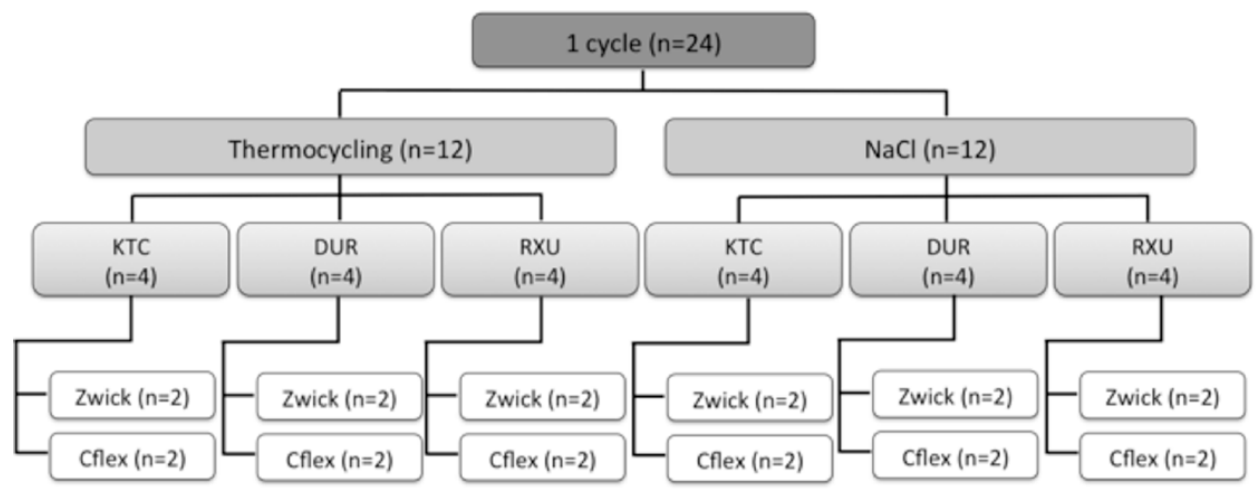

Figure 5. Detailed workflow scheme for one cycle. 


\subsection{Statistical Analysis}

Statistical analysis was performed using SPSS, version 22.0.0.1 (SPSS Inc., Chicago, IL, USA). A significance level of $p \leq 0.05$ was set. Since the data of the UTM tests were distributed normally (Kolmogorov-Smirnov), multi-factor ANOVA analysis was performed. Furthermore, a post hoc test in form of pairwise comparison was applied. For data measured by CORONAflex, Mann-Whitney $U$ test was performed since data were not distributed normally (Kolmogorov-Smirnov).

\section{Results}

The results and statistical evaluation are illustrated in detail in Table 1a,b and Figure 6a,b.

Table 1. (a) Mean retention forces to remove the specimens using UTM (in Newton). (b) Median number of attempts to remove the specimens with Coronaflex (in attempts).

a

\begin{tabular}{ccccc}
\hline \multirow{2}{*}{$\begin{array}{c}\text { Universal Testing Machine } \\
\text { (UTM) }\end{array}$} & \multicolumn{2}{c}{ SCs } & \multicolumn{2}{c}{ FDPs } \\
\cline { 2 - 5 } & $\begin{array}{c}\text { NaCl } \\
\text { (Mean } \pm \text { SD) }\end{array}$ & $\begin{array}{c}\text { Thermocycling } \\
\text { (Mean } \pm \text { SD) }\end{array}$ & $\begin{array}{c}\text { NaCl } \\
\text { (Mean } \pm \text { SD) }\end{array}$ & $\begin{array}{c}\text { Thermocycling } \\
\text { (Mean } \pm \text { SD) }\end{array}$ \\
\hline KTC & $170 \pm 75$ & $156 \pm 134$ & $352 \pm 57$ & $262 \pm 178$ \\
DUR & $409 \pm 174$ & $306 \pm 175$ & $406 \pm 128$ & $380 \pm 247$ \\
RXU & $265 \pm 62$ & $494 \pm 70$ & $426 \pm 76$ & $508 \pm 122$
\end{tabular}

SD: Standard deviation.

b

\begin{tabular}{ccccc}
\hline \multirow{2}{*}{ CoronaFlex } & \multicolumn{2}{c}{ SCs } & \multicolumn{2}{c}{ FDPs } \\
\cline { 2 - 5 } & $\begin{array}{c}\text { NaCl } \\
\text { Median (Min/Max) }\end{array}$ & $\begin{array}{c}\text { Thermocycling } \\
\text { Median (Min/Max) }\end{array}$ & $\begin{array}{c}\text { NaCl } \\
\text { Median (Min/Max) }\end{array}$ & $\begin{array}{c}\text { Thermocycling } \\
\text { Median (Min/Max) }\end{array}$ \\
\hline KTC & $2(1 / 3)$ & $2(1 / 4)$ & $3(1 / 6)$ & $5(3 / 10)$ \\
DUR & $3(1 / 15)$ & $1(1 / 11)$ & $16(15 / 21)$ & $5(2 / 20)$ \\
RXU & $3(2 / 7)$ & $4(1 / 12)$ & $13(7 / 20)$ & $12(7 / 16)$ \\
\hline
\end{tabular}

The mean value for 9 randomly chosen implants at the mid-axial gap between abutment and crown was $67 \pm 35 \mu \mathrm{m}$ and $39 \pm 15 \mu \mathrm{m}$ for the marginal gap.

Table 1 shows the retention forces and the number of attempts needed for the removal. Decimal numbers are rounded up or down to the nearest number. The $3 \mathrm{~mm}$ and $6 \mathrm{~mm}$ layer of cement of the SCs did not show any statistical significance with ANOVA $(p>0.05)$ and Mann-Whitney $\mathrm{U}(p>0.05)$. Therefore, the following analysis was conducted without considering the height of the cement band.

Retention values were recorded between 156 and $352 \mathrm{~N}$ for KTC, 306-409 N for DUR, and 265-508 N for RXU. KTC showed the lowest retention values among all types of cements investigated in this study.

After thermocycling, the number of removal attempts reported the highest number with RXU, which was considered significantly different in comparison to the other types of cements. KTC and DUR showed almost an equal number of removal attempts.

Focusing on the type of restoration, FDPs showed in general higher retention values than SCs after $\mathrm{NaCl}$ storage. These values were statistically significantly different with KTC and RXU, whereas no significant difference was found between both types of restorations when DUR was used. In addition, the number of removal attempts was higher for FDPs, for each cement type, and for both storage methods. Here, DUR required the highest number of removal attempts followed by RXU and KTC.

Artificial aging (simulating the course of one year in vivo) reported an increase in the retention values of RXU but led to a decrease in the retention of both KTC and DUR. The retention decrease in DUR was considered particularly significant. 

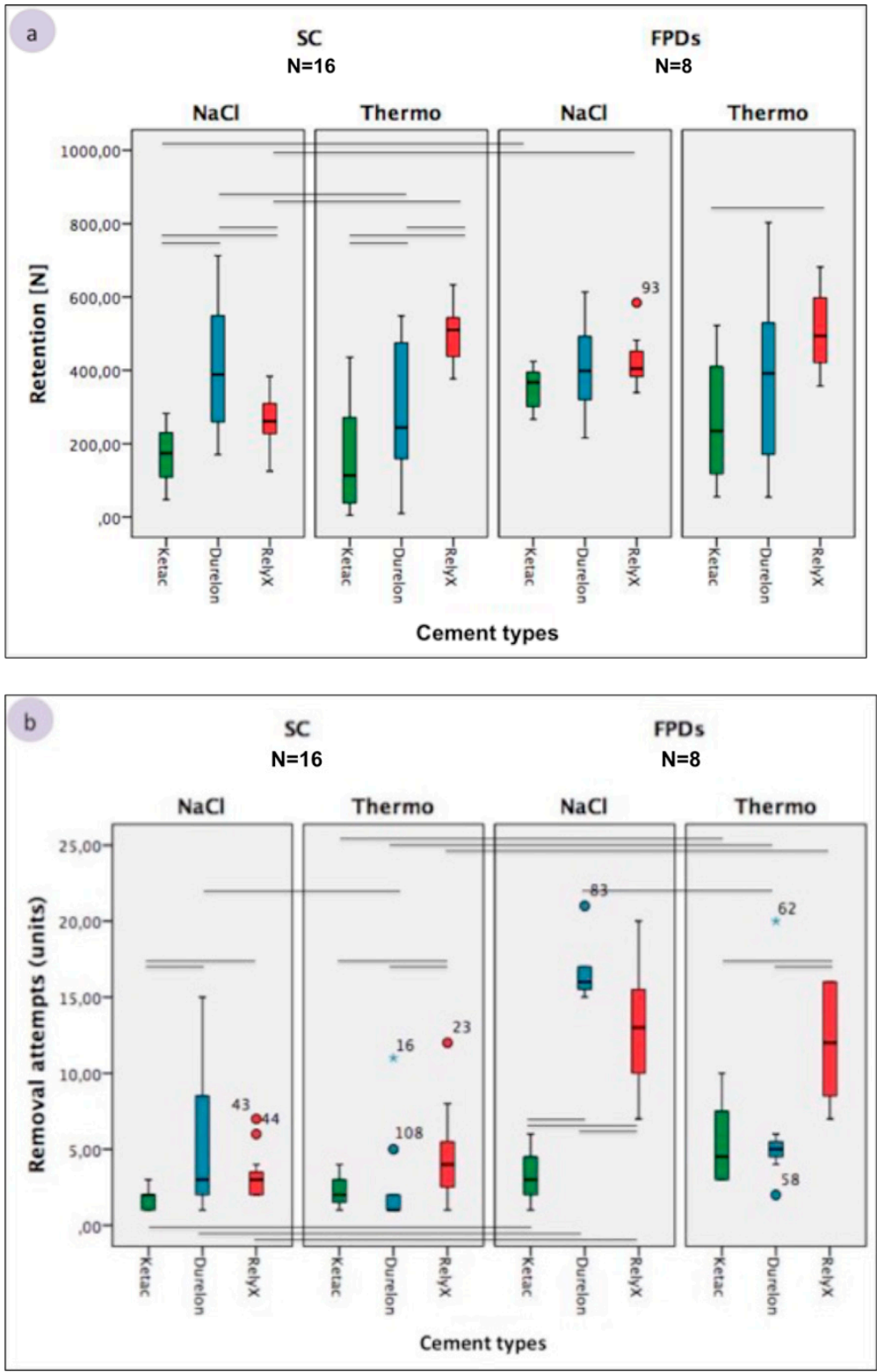

Figure 6. (a) Box-plot graphs of the retention forces needed to remove the specimens with Zwick. All cements and both storages are illustrated. The values of all boxes are between $25 \%$ and $75 \%$ percentile. The whiskers represent the minimum and maximum value and the line inside the box shows the median. Outliers were plotted with points. Groups connected by lines are significant different $(p \leq 0.05)$. (b) Box-plot graphs of the attempt numbers needed to remove the specimens with CoronaFlex. All cements and both storages are illustrated. The values of all boxes are between $25 \%$ and $75 \%$ percentile. The whiskers represent the minimum and maximum value and the line inside the box shows the median. Outliers were plotted with points. Groups connected by lines are significant different $(p \leq 0.05)$.

\section{Discussion}

In the present in vitro study, the retrievability of different implant-retained restorations (SCs and multi-unit FDPs) cemented with three different cements (glass-ionomer/KTC, polycarboxylate/DUR, and self-adhesive resin cement/RXU) was investigated. Both hypotheses had to be rejected since thermocycling influenced the retention of all investigated cements. Moreover, a correlation between the type of restoration and retention could be found, as FDPs showed in general higher retention values than SCs. Several studies have been recently published concerning this topic, however, there is a lack of informa- 
tion regarding the direct comparison between the retrievability of both restoration types (SCs, FDPs). As most studies investigated only single crowns or used modified single crown constructions in the form of a proximal extension to simulate the removal of an FDP $[25,26,33-35]$. Here, zinc phosphate and glass ionomer cement were found to be the most suitable for semi-permanent cementation, whereas polycarboxylate cement provided the most durable cementation [26]. One of the possible explanations for different degrees of retrievability was the physical property of the cement, which may have affected the adhesion of such cements to different surfaces. One of the limitations of this study was the lack of artificial aging, which would have helped gain a better understanding of the different adhesion phenomena of the cements. In a recent study, Mehl et al. also confirmed the use of glass ionomer cement as a semipermanent cement. Here, four different types of commercially available cements were subjected to artificial aging and investigated. It was reported that glass ionomer and resin cement (without priming) fulfilled the requirements for semipermanent cementation indicating that they could potentially be retrieved with a clinically applicable removal device [25].

In this study, different dental cements were investigated in order to find out which could fulfill the requirements of adequate retention of the restoration to the implant and predictable removability of the restoration, whenever required. This was tested using two different removal devices (Zwick, Cflex). In addition, the effect of "cement aging" was simulated in the form of thermocycling, representing one year of service in vivo [31].

The results of this study showed that the retentiveness levels of the luting agents differed significantly. After "cement-aging", SCs cemented with adhesive resin cement (RXU) showed the highest retention values, followed by polycarboxylate (DUR) and glass ionomer cement (KTC). In general, most authors proposed that glass ionomer cement is the most suitable as a "semi-permanent" cement $[25,26,33]$. However, according to our data, polycarboxylate (DUR) could also be considered as a semi-permanent cement, but only after a certain usage period. During the first year of cementation, DUR shows to be strong and highly retentive. However, this is significantly decreased after an aging period of one year. Moreover, KTC showed much better constancy in terms of retrievability, whereas DUR revealed a statistically significant difference in the number of removal attempts for both SCs and FDPs. This indicates and confirms the semi-permanent property of the cement after a certain period of aging. Here, it is important to mention that RXU, in all instances, showed higher retention values and a higher number of removal attempts after thermocycling. These retention values contradict those reported previously by Mehl et al. in which RXU revealed a retentive strength equal to that of provisional eugenol-free zinc oxide cement [26].

Several factors may have influenced the results of this in vitro study, including the crown abutment gap, the type of restoration, type of storage as well as the removal technique. A detailed description of each factor and its effect on the retention force of the cements are provided below:

\subsection{Crown-Abutment Gap}

Since the gap between an abutment and its crown may influence the retrievability of cemented crowns $[35,36]$, it was considered necessary to check the gap dimensions. The measured marginal and mid-axial discrepancies between the restorations and the implant abutments in this study (mid-axial gap: $67 \pm 35 \mu \mathrm{m}$ and marginal gap: $39 \mu \mathrm{m} \pm 15 \mu \mathrm{m}$ ) were similar to data of other studies measuring the discrepancies between natural tooth abutments and crown restorations [37,38] or implant abutments and their restorations [39,40]. It has been reported that a cement film thickness of 50 to $100 \mu \mathrm{m}$ for resin and glass ionomer cements, and 80 to $100 \mu \mathrm{m}$ for polycarboxylate cement does not affect the retention forces of restorations [36]. Furthermore, a precise fit results in higher retention forces and the loss of passive fit, which might hinder the removal of the restorations [35]. Thus, representation for good clinical circumstances was given by the here used restorations and implant abutments. 


\subsection{Restoration Material and Abrasion}

Another factor, which could influence the test results was that the restorations used in this study were sandblasted for cleaning purposes after each test before performing the next cementation step, since air abrasion before cementation is a common clinical procedure [26]. Therefore, the amount of abrasion of the inner surfaces caused by cleaning must be considered as a potential impact factor. Regarding this, it has been reported that the wear appears to be insignificant; nevertheless, it has to be taken into consideration that there might be a possible reduction in fit and retention force of the restorations [41], especially due to the repeated testing. To counter this, the frameworks in this study were cast from a hard $\mathrm{CoCr}$ alloy, which is known to be resistant to air abrasion [42].

\subsection{Removal Technique}

In order to simulate the clinical situation as much as possible, the implant-supported restorations were investigated using instruments with high pressure, high impact, and a short duration of force. Therefore, not only a universal testing machine (Zwick), which uses a constant removing force with a long duration of force, but also a clinical device (Coronaflex), which uses air pressure to deliver a high impact onto a dental restoration, was used [26,35].

Results of both tests have to be interpreted with caution since both tests cannot reproduce all oral factors that occur during the removal of a crown, which is cemented onto an implant abutment in vivo. Several different aspects have to be considered under in vivo conditions. One of them is bone elasticity, which allows part of the applied force to be absorbed by the surrounding bone. In this study, the used models in the laboratory had to be fixed to guarantee an equal reference point. Consequently, the authors assume that the applied force was transmitted mainly to the cement layer. This might have eased the removal in contrast to the clinical situation. No less important is the mobility of the patient's head or mandible during this procedure. Those influential coefficients make the exact transferability of the results difficult.

\subsection{Type of Cement}

For specimens cemented with KTC, thermocycling did not influence the retrievability in any case. However, the kind of restoration was significant for the stability. The current data showed that the FDPs were harder to remove than the SCs in almost every case. Moreover, specimens with KTC had the lowest retention force compared to all cements. Similar results with KTC are given in the literature when compared to DUR [41]. KTC contains polyacrylic acid and glass fill body $\left(\mathrm{Al}^{3+}\right.$ and $\left.\mathrm{Ca}^{2+}\right)$. The metal ions of the glass fill body and the acid groups compose a soluble gel. During the setting reaction, this gel becomes insoluble and hydrophobic. This may explain the resistance to thermocycling. Therefore, based on our results and the data available in the literature, it can be confirmed that KTC can be shown as a "semi-permanent" cement.

On the other hand, specimens cemented with DUR and stored in $\mathrm{NaCl}$, needed by trend the highest retention force to dislodge, followed by RXU and KTC. This trend was also observed in previous studies [26,43,44]. In addition, the number of attempts needed for the removal of the restorations stored in $\mathrm{NaCl}$ with Coronaflex was the highest. It is unknown why the number of attempts and the force needed for removing restorations cemented with DUR, which were stored for $24 \mathrm{~h}$ in $\mathrm{NaCl}$, was higher than for other cements. Differences in physical properties such as adhesion or cohesion might be the reason. This type of cement contains polyacrylic acid and zinc oxide. The acid can adhere to the enamel/dentin structure by the chelation of calcium ions or to metal substrates by the chelation of metallic ions (e.g., $\mathrm{CoCr}$ ) [45]. During the setting, the polyacrylic acid connects with zinc oxide to form a mesh. Interestingly, it can be shown, that, except in a single case, DUR is sensitive to thermocycling. Therefore, in almost all cases, the retention force and the number of attempts needed for the removal of restorations decreased significantly after 10,000 thermocycles compared to the storage in $\mathrm{NaCl}$. This can especially be monitored 
when testing the retrievability with Coronaflex. In general, when comparing the influence of the two different storages ( $\mathrm{NaCl}$ and thermocycling), the most substantial changes were found with DUR after thermocycling.

Similar results have been previously provided in the literature. An in vivo study [46], which used Coronaflex to remove single crowns after 8 months in the patient's mouth, resulted also in a small number of needed attempts to remove the crowns, which were cemented with DUR. Another in vitro study [24] used a universal testing machine to retrieve superstructures from an abutment, which were treated with thermocycling on a chewing machine. Compared to the other definitive cements, specimens with DUR needed the lowest force to be removed. However, other studies have reported no reduction in retention forces for DUR [33]. Factors such as the abutment height or different thermocycling used could be possible reasons.

In the present study, it can be assumed that thermocycling affects DUR when it is only used on a single crown. The additional abutment on the FDPs seemed to have a stabilizing character to the slow tensile force, but not to the high impact of the Coronaflex hits.

Regarding RXU in a previous study, a comparison of RXU to other cements showed a surprising result. After thermocycling, RXU, which is known as a definitive cement, needed a similar number of attempts with the Coronaflex to be removed, like other temporary cements [26].

In contrast to the above-mentioned studies, a direct comparison of both results is possible in this study. Single crowns cemented with RXU and treated with both storages showed a significant increase in retention force after thermocycling, when tested with Zwick. On the other hand, the number of attempts that were needed with the Coronaflex was unchanged. It can be assumed that an addition in retention force does not result in an increase in needed attempts with the Coronaflex. Although this effect could not be shown for FDPs, it might be important for the choice of the clinician when cementing single crowns. KTC and DUR did not show similar interactions. The formula of RXU contains negatively charged phosphoric acid groups of the methacrylate monomers, which interlock to $\mathrm{CoCr}$ surfaces of the framework. Moreover, after the radical polymerization reaction, the condition turns from a hydrophilic into a hydrophobic, which stabilizes the cement during the wet setting while thermocycling.

The limitation of the study was the small sample size, which may have led to a high range of retention values and standard deviations. This seems to be common for this kind of study and has been discussed in many studies before [34,44,47]. Therefore, follow-up studies with more specimens in each group are needed. Furthermore, in vivo studies are needed to verify the data.

\section{Conclusions}

Within the limitations of this in vitro study, it can be concluded that:

1. The type of restoration influences the retention and retrievability, as FDPs showed higher retention values and required an increased number of removal attempts in comparison to SCs.

2. For SCs, artificial aging with thermocycling resulted in a significant increase in retention for RXU, whereas the retention of both KTC and DUR was decreased.

3. Glass ionomer can be used as a semipermanent cement for both SCs and FDPs.

4. Polycarboxylate cement can be considered as a semi-permanent cement after an aging period of one year.

Author Contributions: Conceptualization, S.W. and T.T.; methodology, T.T.; validation, T.T.; formal analysis, S.B. and T.T.; investigation, J.S.; data curation, S.B. and T.T.; writing—original draft preparation, S.B., J.S. and T.T.; writing—review and editing, S.B. and T.T.; visualization, J.S. and T.T.; supervision, T.T.; project administration, S.W. and T.T.; funding acquisition, S.W. and T.T. All authors have read and agreed to the published version of the manuscript. 
Funding: This research was partially funded by the Oral Reconstruction Foundation (formally Camlog Foundation), Grant ref. CF21006. The company 3M ESPE, Germany supported the study with cementation materials.

Institutional Review Board Statement: Not applicable.

Informed Consent Statement: Not applicable.

Acknowledgments: The authors express their thanks to Andreas Rübben from the Department of Prosthodontics and Franz Jungwirth from the Department of Dental Materials and Biomaterial Research, University Hospital RWTH Aachen for their assistance with the experiments.

Conflicts of Interest: The authors declare no conflict of interest.

\section{References}

1. Fueki, K.; Kimoto, K.; Ogawa, T.; Garrett, N.R. Effect of implant-supported or retained dentures on masticatory performance: A systematic review. J. Prosthet. Dent. 2007, 98, 470-477. [CrossRef]

2. Bragger, U.; Burgin, W.B.; Hammerle, C.H.F.; Lang, N.P. Associations between clinical parameters assessed around implants and teeth. Clin. Oral Implants Res. 1997, 8, 412-421. [CrossRef] [PubMed]

3. Derks, J.; Tomasi, C. Peri-implant health and disease. A systematic review of current epidemiology. J. Clin. Periodontol. 2015, 42 (Suppl. 16), S158-S171. [CrossRef] [PubMed]

4. Kordbacheh Changi, K.; Finkelstein, J.; Papapanou, P.N. Peri-implantitis prevalence, incidence rate, and risk factors: A study of electronic health records at a U.S. dental school. Clin. Oral Implants Res. 2019, 30, 306-314. [CrossRef] [PubMed]

5. Hamed, M.T.; Abdullah Mously, H.; Khalid Alamoudi, S.; Hossam Hashem, A.B.; Hussein Naguib, G. A Systematic Review of Screw versus Cement-Retained Fixed Implant Supported Reconstructions. Clin. Cosmet. Investig. Dent. 2020, 12, 9-16. [CrossRef]

6. Ma, S.; Fenton, A. Screw-versus cement-retained implant prostheses: A systematic review of prosthodontic maintenance and complications. Int. J. Prosthodont. 2015, 28, 127-145. [CrossRef]

7. Sherif, S.; Susarla, H.K.; Kapos, T.; Munoz, D.; Chang, B.M.; Wright, R.F. A systematic review of screw- versus cement-retained implant-supported fixed restorations. J. Prosthodont. 2014, 23, 1-9. [CrossRef]

8. Wittneben, J.G.; Millen, C.; Bragger, U. Clinical performance of screw- versus cement-retained fixed implant-supported reconstructions-A systematic review. Int. J. Oral Maxillofac. Implants 2014, 29, 84-98. [CrossRef]

9. Taylor, T.D.; Agar, J.R.; Vogiatzi, T. Implant prosthodontics: Current perspective and future directions. Int. J. Oral Maxillofac. Implants 2000, 15, 66-75.

10. Chee, W.W.; Torbati, A.; Albouy, J.P. Retrievable cemented implant restorations. J. Prosthodont. 1998, 7, 120-125. [CrossRef]

11. Zarb, G.A.; Schmitt, A. The longitudinal clinical effectiveness of osseointegrated dental implants: The Toronto study. Part III: Problems and complications encountered. J. Prosthet. Dent. 1990, 64, 185-194. [CrossRef]

12. Keith, S.E.; Miller, B.H.; Woody, R.D.; Higginbottom, F.L. Marginal discrepancy of screw-retained and cemented metal-ceramic crowns on implants abutments. Int. J. Oral Maxillofac. Implants 1999, 14, 369-378. [PubMed]

13. Gervais, M.J.; Wilson, P.R. A rationale for retrievability of fixed, implant-supported prostheses: A complication-based analysis. Int. J. Prosthodont. 2007, 20, 13-24. [PubMed]

14. Torrado, E.; Ercoli, C.; Al Mardini, M.; Graser, G.N.; Tallents, R.H.; Cordaro, L. A comparison of the porcelain fracture resistance of screw-retained and cement-retained implant-supported metal-ceramic crowns. J. Prosthet. Dent. 2004, 91, 532-537. [CrossRef]

15. Walton, J.N.; MacEntee, M.I. Problems with prostheses on implants: A retrospective study. J. Prosthet. Dent. 1994, 71, 283-288. [CrossRef]

16. Duyck, J.; Naert, I. Influence of prosthesis fit and the effect of a luting system on the prosthetic connection preload: An in vitro study. Int. J. Prosthodont. 2002, 15, 389-396.

17. Wood, M.R.; Vermilyea, S.G. A review of selected dental literature on evidence-based treatment planning for dental implants: Report of the Committee on Research in Fixed Prosthodontics of the Academy of Fixed Prosthodontics. J. Prosthet. Dent. 2004, 92, 447-462. [CrossRef]

18. Chee, W.; Jivraj, S. Screw versus cemented implant supported restorations. Br. Dent. J. 2006, 201, 501-507. [CrossRef]

19. Linkevicius, T.; Vindasiute, E.; Puisys, A.; Peciuliene, V. The influence of margin location on the amount of undetected cement excess after delivery of cement-retained implant restorations. Clin. Oral Implants Res. 2011, 22, 1379-1384. [CrossRef]

20. Wilson, T.G., Jr. The positive relationship between excess cement and peri-implant disease: A prospective clinical endoscopic study. J. Periodontol. 2009, 80, 1388-1392. [CrossRef]

21. Chee, W.; Felton, D.A.; Johnson, P.F.; Sullivan, D.Y. Cemented versus screw-retained implant prostheses: Which is better? Int. J. Oral Maxillofac. Implants 1999, 14, 137-141. [PubMed]

22. Bresciano, M.; Schierano, G.; Manzella, C.; Screti, A.; Bignardi, C.; Preti, G. Retention of luting agents on implant abutments of different height and taper. Clin. Oral Implants Res. 2005, 16, 594-598. [CrossRef] [PubMed]

23. Breeding, L.C.; Dixon, D.L.; Bogacki, M.T.; Tietge, J.D. Use of luting agents with an implant system: Part I. J. Prosthet. Dent. 1992, 68, 737-741. [CrossRef]

24. Pan, Y.H.; Lin, C.K. The effect of luting agents on the retention of dental implant-supported crowns. Chang. Gung Med. J. 2005, 28, 403-410. 
25. Mehl, C.; Ali, S.; El Bahra, S.; Harder, S.; Vollrath, O.; Kern, M. Is There a Correlation Between Tensile Strength and Retrievability of Cemented Implant-Retained Crowns Using Artificial Aging? Int. J. Prosthodont. 2016, 29, 83-90. [CrossRef]

26. Mehl, C.; Harder, S.; Wolfart, M.; Kern, M.; Wolfart, S. Retrievability of implant-retained crowns following cementation. Clin. Oral Implants Res. 2008, 19, 1304-1311. [CrossRef]

27. Winkler, S.; Ring, K.; Ring, J.D.; Boberick, K.G. Implant screw mechanics and the settling effect: Overview. J. Oral Implantol. 2003, 29, 242-245. [CrossRef]

28. Brawek, P.K.; Wolfart, S.; Endres, L.; Kirsten, A.; Reich, S. The clinical accuracy of single crowns exclusively fabricated by digital workflow-the comparison of two systems. Clin. Oral Investig. 2013, 17, 2119-2125. [CrossRef]

29. Holmes, J.R.; Bayne, S.C.; Holland, G.A.; Sulik, W.D. Considerations in measurement of marginal fit. J. Prosthet. Dent. 1989, 62, 405-408. [CrossRef]

30. Brunzel, S.; Yang, B.; Wolfart, S.; Kern, M. Tensile bond strength of a so-called self-adhesive luting resin cement to dentin. J. Adhes. Dent. 2010, 12, 143-150.

31. Gale, M.S.; Darvell, B.W. Thermal cycling procedures for laboratory testing of dental restorations. J. Dent. 1999, 27, 89-99. [CrossRef]

32. Xie, C.; Han, Y.; Zhao, X.Y.; Wang, Z.Y.; He, H.M. Microtensile bond strength of one- and two-step self-etching adhesives on sclerotic dentin: The effects of thermocycling. Oper Dent. 2010, 35, 547-555. [CrossRef] [PubMed]

33. Mehl, C.; Harder, S.; Shahriari, A.; Steiner, M.; Kern, M. Influence of abutment height and thermocycling on retrievability of cemented implant-supported crowns. Int. J. Oral Maxillofac. Implants 2012, 27, 1106-1115. [PubMed]

34. Schiessl, C.; Schaefer, L.; Winter, C.; Fuerst, J.; Rosentritt, M.; Zeman, F.; Behr, M. Factors determining the retentiveness of luting agents used with metal- and ceramic-based implant components. Clin. Oral Investig. 2013, 17, 1179-1190. [CrossRef]

35. Wolfart, M.; Wolfart, S.; Kern, M. Retention forces and seating discrepancies of implant-retained castings after cementation. Int. J. Oral Maxillofac. Implants 2006, 21, 519-525.

36. Mehl, C.; Harder, S.; Steiner, M.; Vollrath, O.; Kern, M. Influence of cement film thickness on the retention of implant-retained crowns. J. Prosthodont. 2013, 22, 618-625. [CrossRef]

37. Albert, F.E.; El-Mowafy, O.M. Marginal adaptation and microleakage of Procera AllCeram crowns with four cements. Int. J. Prosthodont. 2004, 17, 529-535. [CrossRef]

38. Ferrari, M. Cement thickness and microleakage under Dicor crowns: An in vivo investigation. Int. J. Prosthodont. 1991, 4, 126-131.

39. Faot, F.; Suzuki, D.; Senna, P.M.; da Silva, W.J.; de Mattias Sartori, I.A. Discrepancies in marginal and internal fits for different metal and alumina infrastructures cemented on implant abutments. Eur. J. Oral Sci. 2015, 123, 215-219. [CrossRef]

40. Nejatidanesh, F.; Shakibamehr, A.H.; Savabi, O. Comparison of Marginal and Internal Adaptation of CAD/CAM and Conventional Cement Retained Implant-Supported Single Crowns. Implant Dent. 2015, 25, 103-108. [CrossRef]

41. Mehl, C.; Harder, S.; Schwarz, D.; Steiner, M.; Vollrath, O.; Kern, M. In vitro influence of ultrasonic stress, removal force preload and thermocycling on the retrievability of implant-retained crowns. Clin. Oral Implants Res. 2012, 23, 930-937. [CrossRef] [PubMed]

42. Kern, M.; Thompson, V.P. Sandblasting and silica-coating of dental alloys: Volume loss, morphology and changes in the surface composition. Dent Mater 1993, 9, 151-161. [CrossRef]

43. Akca, K.; Iplikcioglu, H.; Cehreli, M.C. Comparison of uniaxial resistance forces of cements used with implant-supported crowns Int. J. Oral Maxillofac. Implants 2002, 17, 536-542. [PubMed]

44. Mansour, A.; Ercoli, C.; Graser, G.; Tallents, R.; Moss, M. Comparative evaluation of casting retention using the ITI solid abutment with six cements. Clin. Oral Implants Res. 2002, 13, 343-348. [CrossRef]

45. Moser, J.B.; Brown, D.B.; Greener, E.H. Short-Term Bond Strengths between Adhesive Cements and Dental Alloys. J. Dent. Res. 1974, 53, 1377-1386. [CrossRef]

46. Worni, A.; Gholami, H.; Marchand, L.; Katsoulis, J.; Mericske-Stern, R.; Enkling, N. Retrievability of implant-supported crowns when using three different cements: A controlled clinical trial. Int. J. Prosthodont. 2015, 28, 22-29. [CrossRef]

47. Dudley, J.E.; Richards, L.C.; Abbott, J.R. Retention of cast crown copings cemented to implant abutments. Aust. Dent. J. 2008, 53, 332-339. [CrossRef] 